\title{
ASSESSMENT OF INVASIVE PLANT SPECIES, OPUNTIA SPP. (PRICKLY PEAR) IN RAYDAH PROTECTED AREA, ASEER, SAUDI ARABIA
}

\author{
ALWADAI, H. M. \\ Department of Biology, College of Science, King Khalid University, Abha, Saudi Arabia \\ (e-mail: hmalwadai@kku.edu.sa; hmwadei@gmail.com; phone: +966-17-241-7242; fax: +966- \\ 17-241-8412) \\ (Received $9^{\text {th }}$ Mar 2019; accepted $13^{\text {th }}$ Jun 2019)
}

\begin{abstract}
Raydah protected area in an important declared protected area in Aseer area, Kingdom of Saudi Arabia that is rich in biodiversity, and provides habitat for nine of the ten indigenous bird species in the kingdom. Invasive plant Opuntia spp. in Raydah could threaten the natural balance among the indigenous species and thereafter affect the biological components of the ecosystem. This study evaluates the prevalence of invasive species and vegetation cover trends in Raydah protected area to identify possible interventions to conserve and protect the protected area. The results provide important and necessary information for the conservation and management of the Raydah Area and the Aseer Area's southwestern highlands. The study has demonstrated the potential of sentinel sensor for detection and mapping of invasive species such as Opuntia spp. with desirable accuracy. This encouraging result demonstrated the feasibility of developing a semi-automated process for mapping and analysing the distribution of Opuntia spp. and found better results compared to multispectral data with very high resolution. Assessment of the current situation of the Opuntia spp. in the protected area will provide scientific data base for future management plans to combat and control invasive plants and protect the protected area from their adverse effects.
\end{abstract}

Keywords: ecosystem, biodiversity, Sarawat Mountains, Juniperus procera, Sentinel satellite data

\section{Introduction}

Invasive plants pose significant threats to natural ecosystems (Gurevitch and Padilla, 2004), biodiversity (Gaertner et al., 2009), forests (Peerbhay et al., 2016), rangelands and agricultural productivity (Pimentel et al., 2005). In addition, invasive plants are known to reduce the abundance of native plant species (Gaertner et al., 2009), alter soil properties (Pejchar and Mooney, 2009), and homogenize the biodiversity of invaded landscapes (Joshi et al., 2004). Invasive species are the species, subspecies that occur outside their natural range and potential for dispersal, and include any part of those species that may survive and then reproduce (Turlings, 2000). The non-native species invasion process took place in three phases: arrival, establishment and spread.

The southwestern parts of the Kingdom of Saudi Arabia have witnessed negative impacts of invasive species on forest ecosystems over the past few decades. Among them, the Opuntia spp. is one of the most serious invasive plant species, colonizing large forest areas in the highlands of the Sarawat Mountains in the southwestern parts of the kingdom. It is rich in dense vegetation as part of the southwest mountain ecosystem of the Sarwat, and constitutes the highest density of vegetation and diversity in the kingdom. The Sarwat southwest mountains' main high altitude species include Juniperus procera, the main dominant species with a density of 95 percent at elevations of 2000-3000 m above sea level (Aref et al., 2013). It grows in lower elevations with other tree species, such as Acacia spp., Oleaeuropaea ssp. Africana (Mill.) P. Green. Ziziphus spina christi and Tamarix aphylla (El-Juhany and Aref, 2013). El-Juhany and 
Aref (2013) noted that the following species of tree were reported only in the Aseer region: Dobera glabra, Adenium obesum, Mimusop slaurifolia, Ficussy comorus and Tamarindus indica.

In the southwestern highlands, Thomas et al. (2016) reported many invasive species such as Opuntia spp. To evaluate changes in vegetation and the spread of invasive species, it is therefore important to evaluate the status in the Raydah protected area. Invasive species are usually introduced from their native range to new plant species, either intentionally (Surendra et al., 2013) or accidentally, expanding into natural areas and disrupting native plant communities. They are equipped to adapt to new habitats, and with reproductive capacity they can grow aggressively. In the absence of natural enemies, their ability to compete and grow vigorously enables them to expand aggressively. These alien species are usually introduced into an ecosystem through seeds in imported soil, traveller fruits, deliberate introduction of certain species for their products, services or values, dispersal of seeds by natural means, and disposal of waste or soil containing alien plant seeds. Invasive species may have been introduced through human interference in the southwestern highlands of the kingdom and expanded due to clearing vegetation of large areas for road expansion, grazing and felling and removal of endemic forest trees.

Invasive plant expansion Raydah may have catastrophic effects on the habitat of the protected area in terms of overgrowth and displacement of native plants, resulting in disruption of the natural balance of native plant communities. Possible major consequences could include:

- Altering the plant species density and extinction of some species.

- Reducing the genetic base of the endemic species (resulting from biotic and abiotic stresses).

- Impact the balance and composition of endemic plant species - dependent wildlife components.

- Biodiversity reduction can adversely affect wildlife and alter natural processes such as fire or intensity and water flow.

Assessment of the current situation in the Raydah protected area will indicate and reveal the gravity of the situation and indicate possible interventions to control the invasive species Many methods have been developed to control or eradicate invasive species dependent on: available resources, plant species and habitat, and spread severity. These methods include: chemical control of invasive species by systematic herbicides, biological control by imported enemies, mechanical control by machines and hand tools, physical control (hand pulling, water drainage, flooding, burning and shading), or a combination of these methods (Integrated Management). Accordingly, this study address the situation of the invasive species in Raydah, with the general aim of conserving Raydah protected area, as part of an important ecosystem in the southwestern highlands of the kingdom, from their danger and threats. The unique plant association that provides habitat for nine of the ten indigenous bird species of Saudi Arabia should be managed and protected from the aggressiveness of the alien species.

Remote sensing data of high resolution have received considerable attention for invasive species inventory. The multi-date satellite imagery facilitates the monitoring and identification of phenological changes. It may be useful to integrate satellite information with other attributes in GIS to predict the spread of invasive species. Remote sensing of invasive plants has only been successful if the invasive is in a 
riparian, grassland, desert environment, aquatic and wetland where the lack of a tree cover enables the sensors to see the invasive plant unhindered (Bradley and Mustard, 2006). Thus, hindered invasive poses a challenge. Many researchers used hyperspectral data to detect and map invasive species (Lawrence et al., 2004). A practical advantage of using hyperspectral imagery to map invasive species is its capability to determine relative or unmixed components, which can be particularly useful in determining the percentage of species coverage (Peerbhay et al., 2016; Peerbhay et al., 2015; Curatola Fernandez et al., 2013). As noted above, the success of alien invasion remote sensing depends on their unique spectral signatures being identified, facilitated by differences in biophysical and biochemical characteristics (Matongera et al., 2016). Numerous studies (e.g. Matongera et al., 2016; Peerbhay et al., 2016; Niphadkar and Nagendra, 2016; Rocchini et al., 2015; Bradley, 2014; Boyd and Foody, 2011; Joshi et al., 2004) have explored approaches to remote sensing to optimize AIP detection and mapping.

The study aims to evaluate the prevalence of invasive species and vegetation cover trends in Raydah protected area to identify possible interventions to conserve and protect the protected area. The results may provide important and necessary information for the conservation and management of the Raydah Area and the Aseer Area's southwestern highlands. The specific objectives of this study were: to evaluates the usefulness of Sentinel satellite dataset for Opuntia spp. detection and mapping with emphasis on automatic information extraction techniques, establishing a phenological trend for the extraction of understory invasive plant data from temporal Sentinel satellite data (i.e. Opuntia spp.), assessing the usefulness of Sentinel sensor for the detection and mapping of Opuntia spp.

\section{Literature review}

Invasive species are defined as those non-native species that threaten ecosystems, habitats and species (Convention on Biological Diversity, 2008). They have great impact and influence on of the global environmental change (Pysek and Richardson, 2010), seriously affecting ecosystem services that are important to human welfare (Branco et al., 2015; Hejda et al., 2009). Their threats to plant diversity was reported to increase in past decades (Pimentel et al., 2001), due to the increase in exchange of plant material, and consequently their genetic materials among countries (Van Wilgen et al., 2008). Their effect was ranked as second to human interferences in the cause of species endangerment and extinction (IUCN, 2011). The reported hazards include direct threats to human health, and loss or alteration of goods and services regarding fishery, farming, forestry, drinking water, hydrology, climate stabilization, pollination, culture and recreation (McNeely, 2005; Lovell et al., 2006). The invasive species affect and threaten biological diversity by reducing genetic variation and narrowing gene pools to the extinction of endemic species (Sax and Gaines, 2008). Consequently, costs associated with their impacts are very high worldwide.

The management of invasive alien species present a significant challenge for the conservation authorities. The main principles applied to managing invasive species may include: Prevention of invasive species from entering the ecosystem, regular monitoring and rapid response, eradication, and or containment if eradication is not realistic. Some control methods were suggested that range from chemical, biological, physical, manual and integrated management system. Berhanu and Tesfaye (2006) described the dilemma of Prosopis dilemma (an aggressive invasive species) and some controlling methods. 
Similarly, invasive species can affect plant diversity in the Kingdom, and reach reaches its woodlands, forests, grasslands, agriculture lands, islands and inhabited areas (Thomas et al., 2016). They may have significant impacts on ecosystems and agriculture areas by eliminating or displacing many native species, particularly the highlands. The prevailing warm climate and the humid areas can enhance their spread in the kingdom by accelerating rapid seedling growth compared to native populations as indicated by Griffith et al. (2014).

Thomas et al. (2016) stated that "Approximately 37 alien plants have been reported from various habitats of southwestern region, majority of which are associated with specific plant associations". They indicated that on the higher elevations (800 to $2700 \mathrm{~m}$ ) the common exotics according to severity are: "Opuntia spp., N. glauca, Argemone ochroleuca, T. minuta, Verbesina encolioides, Tridax procumbens, Lantana camara, Amaranthus spinosus, Xanthium spinosum, Cenchrus setigerus and Bidens aurea". Further on, they indicated that six species have increased their distribution range both in the lowlands and highlands, and are therefore considered most troublesome ones in Saudi Arabia. The stated species in a descending order of were " $P$. juliflora (Leguminosae), $O$. dellenii (Cactaceae), $N$. glauca (Solanaceae), $T$. portulacastrum (Aizoaceae), O. ficus-indica (Cactaceae) and Argemone ochroleuca (Papaveraceae)".

The entry of invasive species to the highlands of Aseer Area could be attributed to human interferences like clearance of native plants for roads, as mentioned by Kingston and Waldren (2003). This is evident in the presence of some exotics along road sides in the southwestern high ranges (Thomas, 2016). Also, the highlands of Aseer Area was subjected to overgrazing (Abulfatih et al., 1989) and felling of forest trees that could have contributed to spread of opportunistic invasive species. Economic costs from invasive species include direct costs through reduction of ecosystem productivity and management costs. Indirect costs can occur through reduction in services and revenues. The key to reduce the threats and costs of invasive species damage and management is by early detection and rapid response. Warrag et al., 2019 reported the status of dieback of Juniperus procera (African pencil cedar) in natural stands and plantation in Alsouda highlands Saudi Arabia that is near to the studied location. They stated that with time, the NDVI showed a growing trend of greenness, especially in high rainfall seasons. The slope aspect effect was evident in the vegetation's dieback severity and greenness as detected by NDVI data.

\section{Material and methods}

\section{Study area and field survey}

Raydah watershed area, in an important declared protected area in Aseer area, Kingdom of Saudi Arabia (Fig. 1). Among the other protected areas in the kingdom, it has unique plant association and diversity in the highlands of the Sarawat Mountains in the southwestern parts of the kingdom (Mallick, 2016). The studied area is located between latitude of $18^{\circ} 10^{\prime} 50.859^{\prime} \mathrm{N}$ and $18^{\circ} 13^{\prime} 2.58^{\prime \prime} \mathrm{N}$ and longitude of $42^{\circ} 21^{\prime} 58.042^{\prime \prime} \mathrm{E}$ and $42^{\circ} 24^{\prime} 56.197$ 'E and elevations 1330 to 2827 m.a.s.l.

The main features of Raydah protected area is described in Saudi Wildlife Authority as follows:

- It covers an area of $12.17 \mathrm{~km}^{2}$. 
- It protects dense stands of Juniper (Juniperus procera).

- Its unique plant association provides habitat for nine of the ten indigenous bird species of Saudi Arabia.

- Also, the protected area attracts Caracal Lynx, and Arabian wolf.

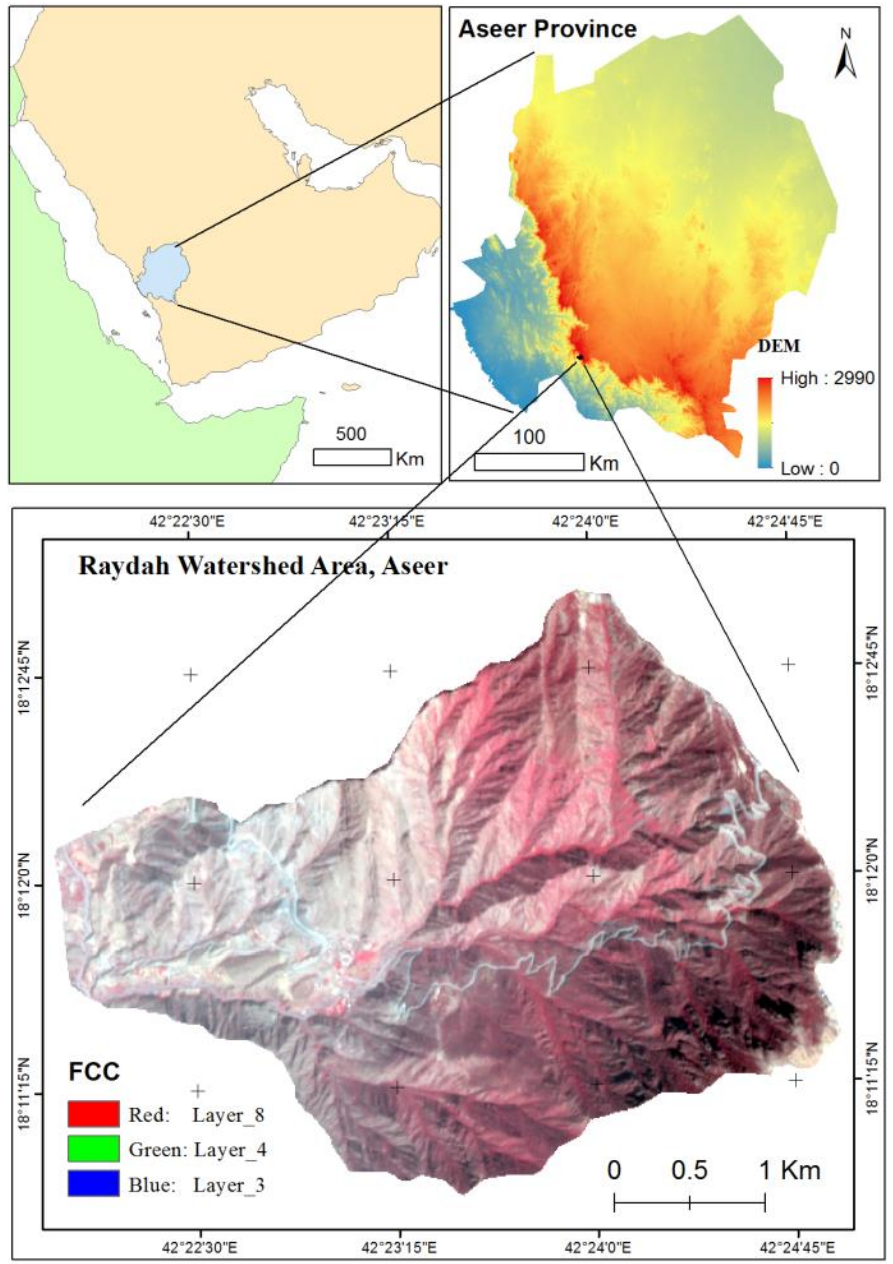

Figure 1. Study area

Sarawat Mountains in the south-western parts of the kingdom receives the highest southwestern monsoon annual rainfall in KSA, with variable annual patterns (Vincent, 2008). Precipitation is mainly from March to June during spring and summer growing seasons (Wheater et al., 1989; Mallick et al., 2014), and mean on the minimum of daily average temperature and mean on the maximum of daily average temperature are 19.3 ${ }^{\circ} \mathrm{C}$ and $29.70{ }^{\circ} \mathrm{C}$, respectively. Rainfall data was obtained from the meteorological station situated $8 \mathrm{~km}$ northwest of the study area (Al-Sooda Station no. 00028, $18^{\circ} 15^{\prime}$ $08^{\prime \prime} \mathrm{N}$ (latitude) and $42^{\circ} 24^{\prime} 15.7$ " E (longitude).

Ground surveys were conducted during 9th February 2019 to 23rd February 2019 for the understanding and distribution of vegetation classes and invasive plants. Figure 2 shows the pictures of important location, in which Juniper procera were severely affected due to Opuntia spp. invasive species. The $50 \times 50 \mathrm{~m}$ size of the sampling areas screened during the field survey. 

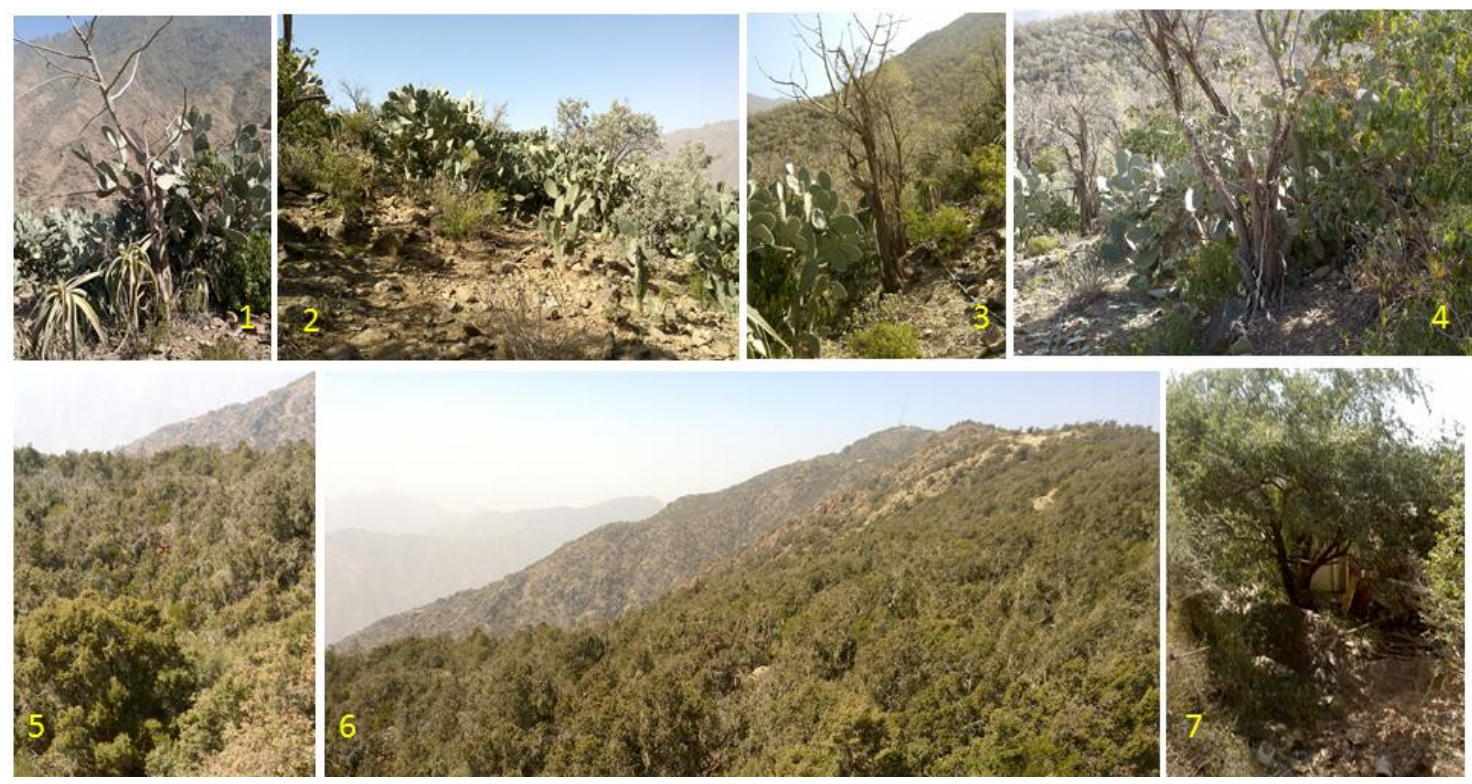

Figure 2. Natural stands status of the Raydah protected area. Opuntia spp. spread and effected Juniperus procera (1-4); Juniperus procera (5-6) and Sidr tree (Ziziphus spina-christi) (7)

\section{Data processing}

The Sentinel-2 level-1C satellite datasets (Level 1C Radiometric and geometric corrections including ortho-rectification and global reference system spatial registration with accuracy of sub-pixels) over the Raydah protected area were used to prepare the Normalized Difference Vegetation Index (NDVI) and Land Use and Land Cover (LULC) maps. The Sentinel-2 L1C product DNs are unsigned integer values of reflectance that that can be multiplied by 10,000 to achieve TOA reflectance values. DEM acquired from ALOS PALSAR Radiometrically Terrain corrected (RTC) DEM. From DEM, elevation $(1330-2827 \mathrm{~m}$, with the mean of $2070 \mathrm{~m})$, slope angle $\left(0^{\circ}\right.$ to $89.54^{\circ}$ with the mean of $29.08^{\circ}$ ) have been calculated using ArcGIS software. For the generation of texture features, the gray level co-occurrence matrix (GLCM) method (Haralick, 1986) with $3 \times 3$ pixel window size was used. The NIR band of Sentinel data generated six texture features, mean, variance, contrast, homogeneity, dissimilarity and entropy as input images. The mean, contrast, homogeneity and variance characteristics displayed maximum information and were therefore taken as classification input images. For maximum likelihood classification, the common training sites selected from the sentinel image were used. For classification accuracy assessment, the classified images were field-checked at 152 locations.

\section{Results and discussion}

Temporary analysis of September, February and April Sentinel satellite dataset (Fig. 3) was conducted to determine a trend in vegetation phenology and to detect changes in the composition and structure of the community. Juniperus procera forest maintained significant foliage during the month of June, resulting in high reflectance from the upper canopy and hindering under-story reflection. From June to October, therefore, it was not possible to separate Opuntia spp. from the story. Therefore, for 
further analysis, Sentinel images were not used. The Juniperus procera, once established, individual trees can survive in hot and dry conditions, but in areas with low rainfall, trees are usually poor in shape and small in size. Where rainfall exceeds Juniperus procera dominated forests are gradually replaced by moister types of evergreen forests in which Juniperus procera becomes increasingly common. This region has the highest average rainfall in Saudi Arabia distributed over 4-6 months during the spring (Aug and Sept and summer growing seasons (March-June), while negligible rainfall during the rest of the year (Wheater et al., 1989; Mallick et al., 2018). Due to partial leaf shedding in the month of February, the under-story reflection also added to the overall reflection (appearing in light reddish tones on standard false color composite (FCC)).

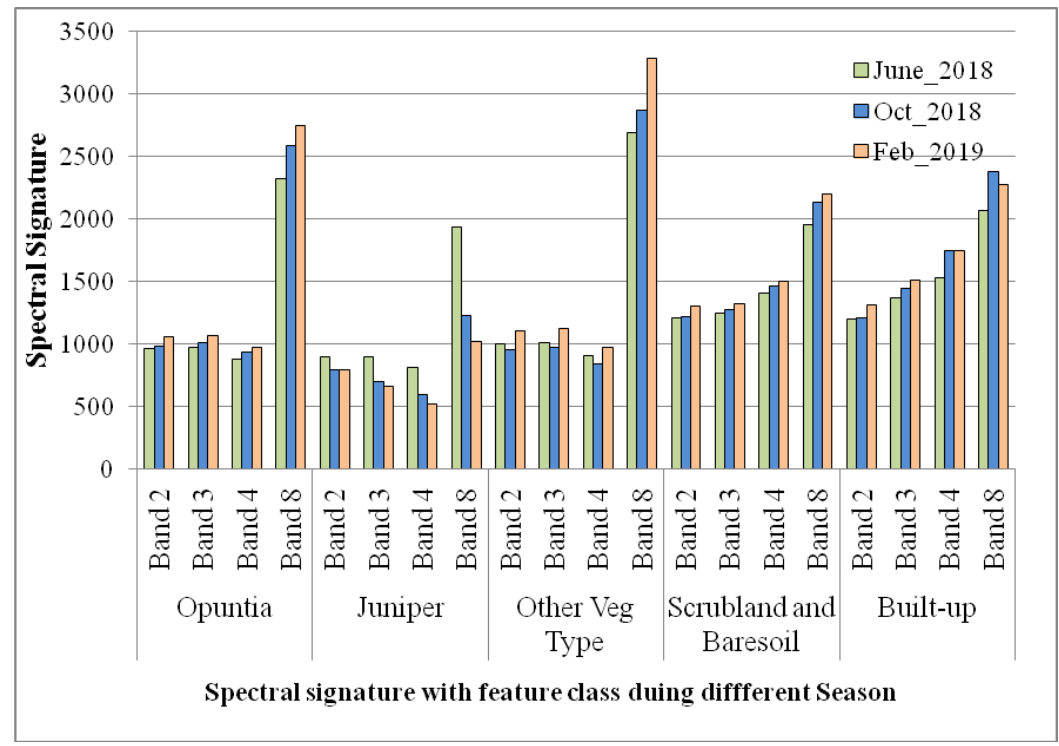

Figure 3. Spectral reflectance of feature classes in June 2018, Oct. 2018 and Feb. 2019

Although vegetation was visible in the February image under the story, it was not possible to delineate boundaries. Maximum reflection from vegetation occurred in the month of June - October due to full extent (moister types of evergreen forests) in evergreen tree (Sidr tree (Ziziphus spina-christi) and Juniperus procera forests (Fig. 4). This pattern in reflection showed that the data acquired between February were suitable for detecting Opuntia spp in the studied area. Every year, the best month varies due to annual temperature and precipitation differences. Statistically compared the Sentinel satellite data for various vegetation classes (Table 1). Opuntia spp's CV was slightly higher than Juniperus procera, indicating that discrimination against Opentia spp was possible to facilitate more accurate discrimination. Table 2 shows the separability of different classes. In bands 3 and 8 of Sentinel data, the 2000 transformed divergence (TD) value showed very good separability of Opuntia spp from Juniperus procera. The 1997 and 1998 TD values between Opuntia spp and other tree (incl. Sidr tree) in bands 3 and 8 showed good separability, respectively. The texture classification was helpful in distinguishing the Opuntia spp from Juniperus procera successfully. In the vegetation classes, Band 8 of Sentinel data had the maximum variability compared to the other three bands (Tables 1 and 2). Band 8 of Sentinel data was therefore selected to analyze texture to extract Opuntia spp. 
Table 1. Transformed values of divergence (TD) showing separability (higher values mean greater separability)

\begin{tabular}{c|c|c|c|c|c|c|c|c}
\hline \multirow{2}{*}{$\begin{array}{c}\text { Satellite } \\
\text { data }\end{array}$} & \multirow{2}{*}{ Bands } & \multirow{2}{*}{ Average } & \multirow{2}{*}{ Minimum } & \multicolumn{6}{|c}{ Class pairs } \\
\cline { 5 - 9 } & & & & $\mathbf{1 : 2}$ & $\mathbf{1 : 3}$ & $\mathbf{1 : 4}$ & $\mathbf{2 : 3}$ & $\mathbf{2 : 4}$ \\
\hline & Band2 & 1997 & 1987 & 2000 & 1987 & 1992 & 2000 & 2000 \\
$\begin{array}{c}\text { Sentinel } \\
\text { data }\end{array}$ & Band3 & 2000 & 1997 & 2000 & 1997 & 2000 & 2000 & 2000 \\
& Band4 & 1876 & 1257 & 2000 & 1257 & 2000 & 2000 & 2000 \\
& Band8 & 2000 & 1998 & 2000 & 1998 & 2000 & 2000 & 2000 \\
\hline
\end{tabular}

1 Opuntia, 2 Juniper, 3 Other tree, 4 Bare soil

Table 2. Spectral reflectance (DN values) statistical analysis from different feature classes

\begin{tabular}{|c|c|c|c|c|c|}
\hline Feature class & $\begin{array}{c}\text { Statistical } \\
\text { parameters }\end{array}$ & Band1 & Band2 & Band3 & Band4 \\
\hline \multirow{7}{*}{ Opuntia spp. } & Min & 1006 & 1022 & 914 & 2304 \\
\hline & Max & 1112 & 1127 & 1037 & 2701 \\
\hline & Mean & 1060.13 & 1067.53 & 975.33 & 2547.80 \\
\hline & Std. dev & 26.402 & 28.658 & 35.479 & 112.579 \\
\hline & $\mathrm{CV}$ & 2.490 & 2.684 & 3.638 & 4.419 \\
\hline & Skewness & 0.129 & 0.615 & 0.041 & -0.722 \\
\hline & Kurtosis & 0.237 & -0.301 & -0.553 & -0.081 \\
\hline \multirow{7}{*}{ Juniperus procera } & Min & 774 & 628 & 491 & 953 \\
\hline & Max & 821 & 696 & 561 & 1168 \\
\hline & Mean & 797.14 & 657.79 & 520.79 & 1016.93 \\
\hline & Std. dev & 11.446 & 13.195 & 16.621 & 51.270 \\
\hline & $\mathrm{CV}$ & 1.394 & 1.896 & 2.963 & 4.390 \\
\hline & Skewness & 0.161 & 0.324 & 0.775 & 1.624 \\
\hline & Kurtosis & -0.524 & 1.802 & 0.834 & 2.912 \\
\hline \multirow{7}{*}{ Other types (incl. Sidr tree) } & Min & 1083 & 1096 & 943 & 3124 \\
\hline & $\operatorname{Max}$ & 1150 & 1148 & 1050 & 3564 \\
\hline & Mean & 1109.88 & 1128.38 & 974.75 & 3290.75 \\
\hline & Std. dev & 21.457 & 16.928 & 34.640 & 170.984 \\
\hline & $\mathrm{CV}$ & 1.933 & 1.500 & 3.554 & 5.196 \\
\hline & Skewness & 0.011 & -0.639 & -0.221 & 0.183 \\
\hline & Kurtosis & 0.144 & 0.411 & -0.355 & -1.451 \\
\hline \multirow{7}{*}{ Scrubland and bare soil } & Min & 1247 & 1248 & 1397 & 2108 \\
\hline & Max & 1358 & 1378 & 1610 & 2296 \\
\hline & Mean & 1305.33 & 1325.13 & 1505.40 & 2200.80 \\
\hline & Std. dev & 29.978 & 35.341 & 58.261 & 66.520 \\
\hline & $\mathrm{CV}$ & 2.297 & 2.667 & 3.870 & 3.023 \\
\hline & Skewness & 0.805 & -0.897 & 1.680 & 1.061 \\
\hline & Kurtosis & 0.552 & 0.624 & 3.207 & -0.467 \\
\hline \multirow{7}{*}{ Built-up } & Min & 1219 & 1429 & 1665 & 2148 \\
\hline & $\operatorname{Max}$ & 1410 & 1572 & 1796 & 2342 \\
\hline & Mean & 1311.33 & 1509.00 & 1750.33 & 2273.00 \\
\hline & Std. dev & 95.657 & 73.000 & 73.962 & 108.448 \\
\hline & $\mathrm{CV}$ & 7.295 & 4.838 & 4.226 & 4.771 \\
\hline & Skewness & 0.297 & -0.991 & -1.719 & -1.704 \\
\hline & Kurtosis & 1.023 & -1.866 & -3.309 & 4.911 \\
\hline
\end{tabular}




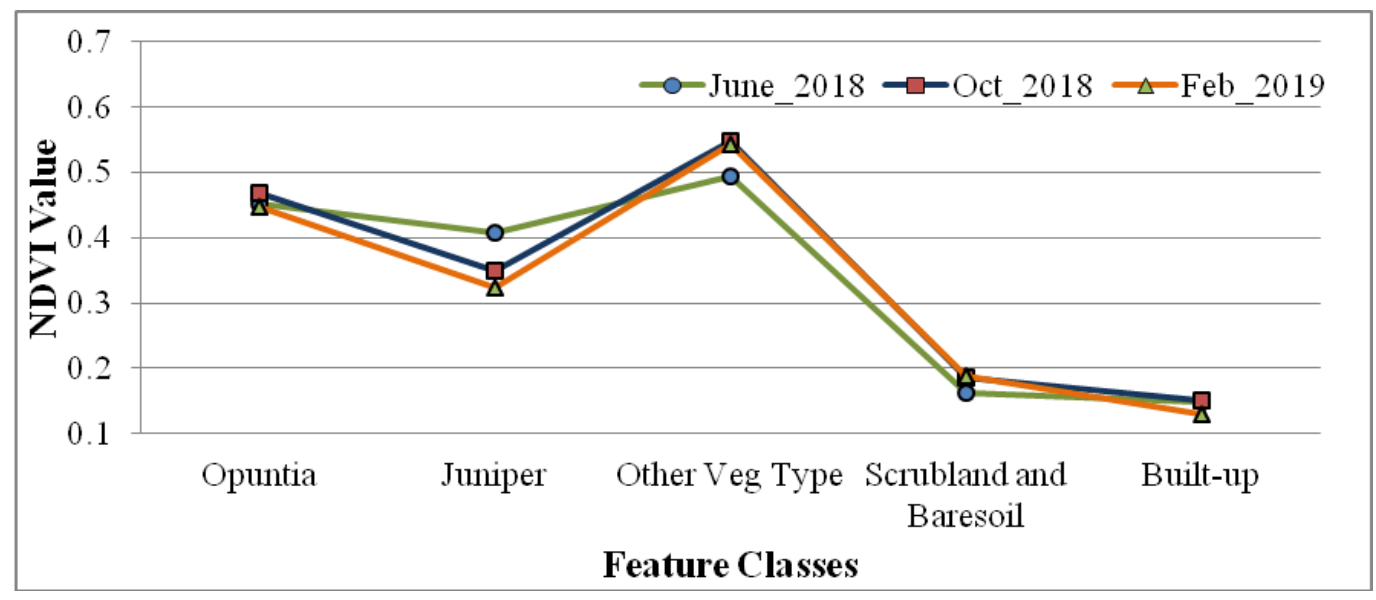

Figure 4. NDVI value of different feature class over different period

Taking into account the objectives, Sentinel satellite dataset were used to prepare the feature class map for the study area, i.e. built-up, exposed rocks, scrublands, Juniperus procera, Opuntia spp. and other tree (incl. Sidr tree). The total area of each category of feature class and percentage was calculated and presented in table. Figure 5 shows the feature class type and the built - up area that also includes the road network lined from east to west direction and the building is mainly located in the western part of the study area towards the low land area. The Juniperus procera $(45 \%)$ was the most dominant class in 2019, followed by scrublands (30.62\%), exposed rocky area (12.66\%) and Opuntia spp. (9.33\%) shown in Table 3. Accuracy assessment was also evaluated to study the performance of the Sentinel sensor in feature class detection (specifically Juniperus procera and Opuntia spp.) for the classified output (Table 4).

Table 3. Area (ha) of feature class estimated from the output of Sentinel sensors

\begin{tabular}{c|c|c|c}
\hline SI. No & Feature class & Area in ha & Percent \% \\
\hline 1 & Built-up & 17.70 & 1.45 \\
2 & Exposed rocks & 154.93 & 12.66 \\
3 & Scrublands & 374.61 & 30.62 \\
4 & Juniperus procera & 550.54 & 45.00 \\
5 & Opuntia spp. & 114.13 & 9.33 \\
6 & Other tree (Incl. Sidr) & 11.53 & 0.94 \\
\hline \multicolumn{2}{l|}{} \\
\hline
\end{tabular}

Table 4. The producer's and user's accuracies

\begin{tabular}{c|c|c|c}
\hline Sl. No & Feature class & Producer's accuracy & User's accuracy \\
\hline 1 & Built-up & 76.52 & 92.85 \\
2 & Exposed rocks & 93.15 & 94.61 \\
3 & Scrublands & 88.90 & 92.47 \\
4 & Juniperus procera & 96.14 & 94.82 \\
5 & Opuntia spp. & 94.69 & 95.72 \\
6 & Other tree (incl. Sidr) & 87.65 & 91.02 \\
\hline
\end{tabular}




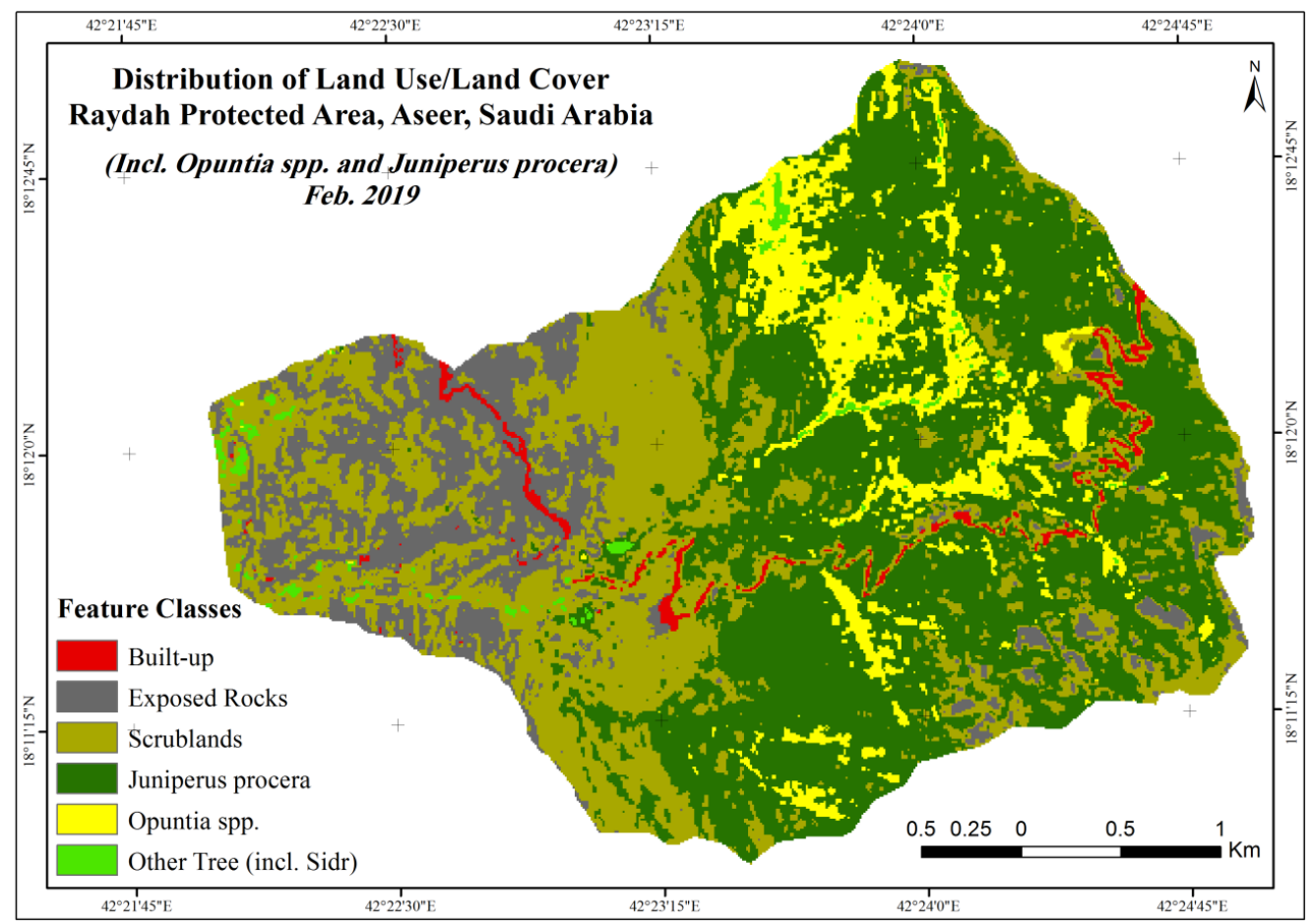

Figure 5. Distribution of land use/land cover in Raydah protected area, Saudi Arabia

The relationship between feature class and topography was analyzed using DEM. Figure shows the results of analysis of feature class in 2019 according to elevation (height). According to Figure 6, Juniperus procera are mostly located in regions with 1951-2827 m of height (Friis, 2009; Negash, 2010). It found as the dominant species in Raydah protected montane vegetation or mixed with other evergreen forests such as Sidr tree (Ziziphus spina-christi). The Opuntia spp. Mostly located in the regions with 1951-2550 m of height. Similarly, scrubland areas, mainly in regions with height of 1330-1950 m. This may be due to soil depth, week geology, and denuded high slope. With increasing altitude, the rock exposed class decreases.

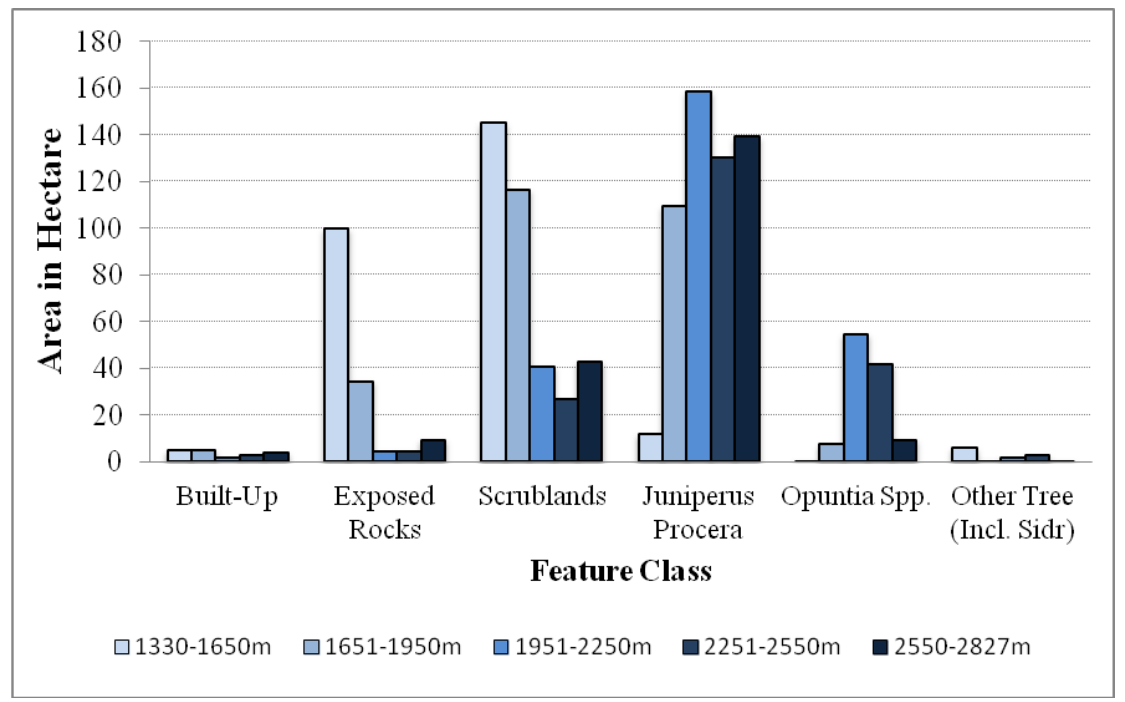

Figure 6. Feature class according to elevation range 
The gradient of the slope influences the feature classes distribution in studied area. Table 5 shows the statistical analysis of slope analysis with feature class at the particular elevation range. The Juniper procera having large variation of slope gradient (ranged approx. $80^{\circ}$ ) between 1951 and $2827 \mathrm{~m}$ of elevation range. Whereas in Opuntia spp. It is found that the variation of slope gradient is low (ranged approx. $48^{\circ}$ ) between 1951 and $2550 \mathrm{~m}$ of elevation range. This finding shows that the growth and expansion of Opuntia spp. maximum at the moderate slope gradient (Fig. 7). It will be noted that the amount of moisture (water) intake tends to slightly decrease with slope increase. On the more gentle slopes, especially the $1.15^{\circ}$ slope or less, the largest intake of water was found. That the degree of slope affects the infiltration. Therefore, it can be concluded that the slope factor influences and accelerates the growth and expansion of Opuntia spp. in the studied area.

Table 5. Statistics of feature class according to topography and slope

\begin{tabular}{|c|c|c|c|c|c|c|c|c|}
\hline & $\begin{array}{c}\text { Statistical } \\
\text { parameters }\end{array}$ & BLT & EX & SCR & Jun. Pro & Op. Sp & OT & $\begin{array}{l}\text { Total } \\
\text { area }\end{array}$ \\
\hline \multirow{4}{*}{$\begin{array}{c}\text { Class-I } \\
\text { Height } \\
1330-1650 \mathrm{~m}\end{array}$} & Area in $\mathrm{Ha}$ & 4.80 & 99.88 & 145.28 & 11.77 & 0.23 & 5.86 & 267.81 \\
\hline & Min Slope & 2.29 & 1.01 & 1.09 & 0.88 & 7.30 & 1.15 & \\
\hline & Max Slope & 46.14 & 89.11 & 89.11 & 42.49 & 19.53 & 38.33 & \\
\hline & Mean Slope & 22.13 & 21.28 & 21.84 & 21.1 & 14.28 & 14.03 & \\
\hline \multirow{4}{*}{$\begin{array}{c}\text { Class-II } \\
\text { Height } \\
1651-1950 \mathrm{~m}\end{array}$} & Area in $\mathrm{Ha}$ & 4.89 & 34.5 & 116.72 & 109.52 & 7.44 & 0.83 & 273.89 \\
\hline & Min Slope & 1.15 & 2.56 & 1.81 & 2.29 & 9.69 & 16.39 & \\
\hline & Max Slope & 41.54 & 88.35 & 67.67 & 69.25 & 39.65 & 35.25 & \\
\hline & Mean Slope & 26.77 & 28.7 & 30.37 & 28.57 & 25.51 & 23.07 & \\
\hline \multirow{4}{*}{$\begin{array}{c}\text { Class-III } \\
\text { Height } \\
1951-2250 \mathrm{~m}\end{array}$} & Area in $\mathrm{Ha}$ & 1.56 & 4.39 & 40.91 & 158.61 & 54.64 & 1.81 & 261.92 \\
\hline & Min Slope & 10.88 & 11.23 & 4.13 & 0.81 & 7.64 & 13.34 & \\
\hline & Max Slope & 44.16 & 46.71 & 89.40 & 89.42 & 54.65 & 50.09 & \\
\hline & Mean Slope & 28.64 & 30.4 & 33.8 & 31.89 & 32.17 & 30.02 & \\
\hline \multirow{4}{*}{$\begin{array}{c}\text { Class-IV } \\
\text { Height } \\
2251-2550 \mathrm{~m}\end{array}$} & Area in $\mathrm{Ha}$ & 2.58 & 4.59 & 26.59 & 130.27 & 41.59 & 2.61 & 208.23 \\
\hline & Min Slope & 18.08 & 17.30 & 10.89 & 3.34 & 9.66 & 20.24 & \\
\hline & Max Slope & 48.24 & 89.49 & 89.49 & 89.48 & 58.33 & 46.13 & \\
\hline & Mean Slope & 31.71 & 41.34 & 35.52 & 34.24 & 34.66 & 32.19 & \\
\hline \multirow{4}{*}{$\begin{array}{c}\text { Class-V } \\
\text { Height } \\
2551-2827 \mathrm{~m}\end{array}$} & Area in $\mathrm{Ha}$ & 3.84 & 9.39 & 42.86 & 139.34 & 9.42 & 0.28 & 205.14 \\
\hline & Min Slope & 2.29 & 0.21 & 0.94 & 0.81 & 5.11 & 21.04 & \\
\hline & Max Slope & 40.15 & 89.49 & 89.55 & 89.54 & 88.53 & 44.01 & \\
\hline & Mean Slope & 28.05 & 30.04 & 25.57 & 30.84 & 26.42 & 30.77 & \\
\hline
\end{tabular}

BLT $=$ Built-Up; EX $=$ Exposed Rocks; SCR $=$ Scrublands; Jun. Pro =Juniperus Procera $;$ Op. $\mathrm{Sp}=$ Opuntia spp OT $=$ Other Tree $($ Incl. Sidr)

Over the past few decades, the southwest part of the Kingdom of Saudi Arabia has experienced negative impacts of invasive species on forest ecosystems, the Opuntia spp. among them. It is one of the most severe invasive plant species, colonizing large forest areas in the Sarawat Mountains highlands in the southwestern parts of the Kingdom. Assessing the current situation in the protected area of Raydah will indicate the gravity of the situation and indicate possible interventions to control the invasive species. 
Remote sensing data of high resolution have received considerable attention for invasive species inventory. The image of the multi-date satellite, i.e. Sentinel dataset facilitates phenological change monitoring and identification. In order to predict invasive species spread, it may be useful to integrate satellite information with other attributes in GIS.
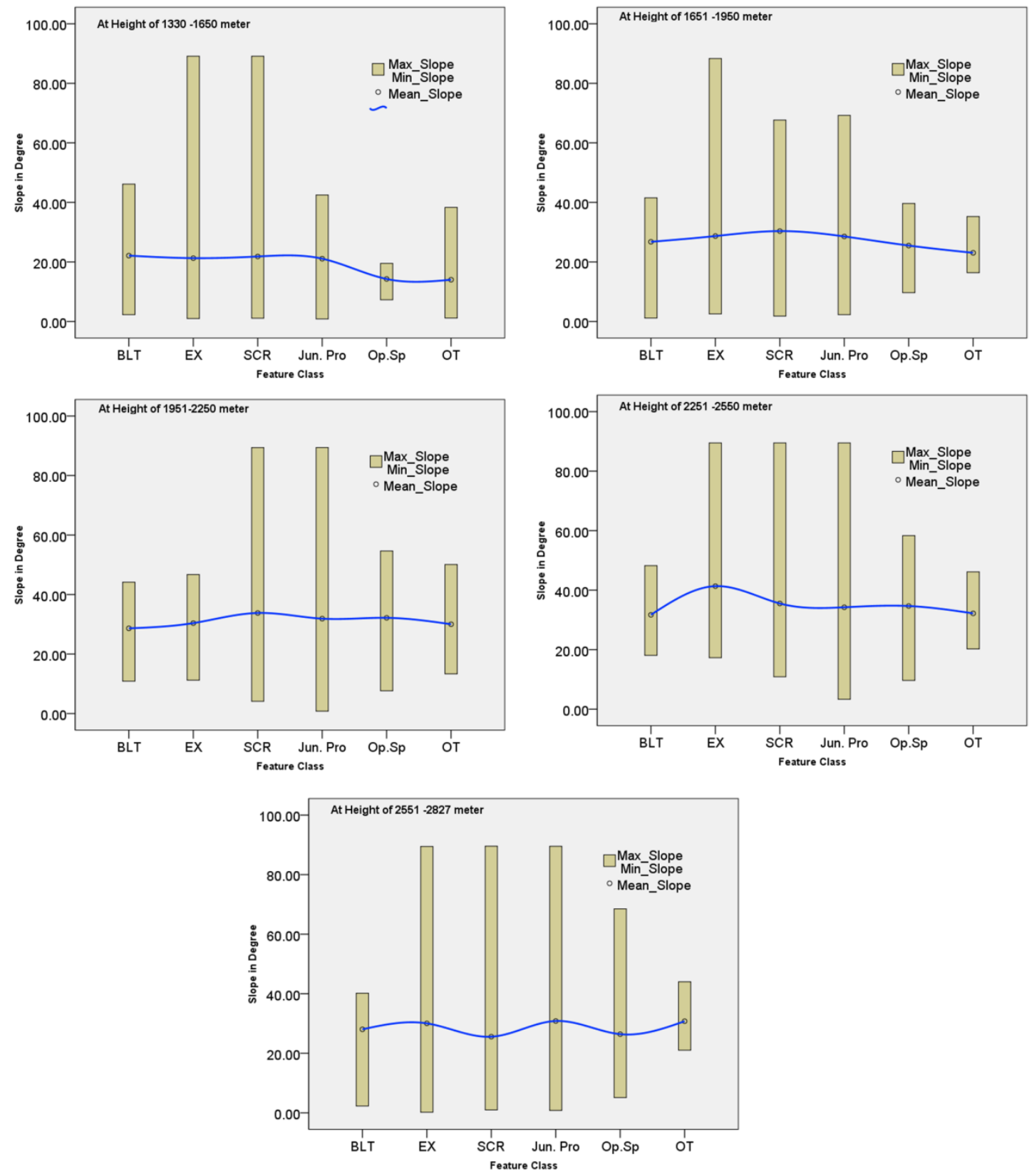

Figure 7. Graphical representation of slope in degree (min, max and mean) at different feature classes

The results of this study showed that Juniperus procera $(45 \%)$ was the most dominant class in 2019 , followed by scrublands $(30.62 \%)$, exposed rocky area $(12.66 \%)$ and Opuntia spp. (9.33\%). The relationship between feature class and topography was 
also analyzed using DEM. Juniperus procera are mostly located in regions with 1951$2827 \mathrm{~m}$ of height. It found as the dominant species in Raydah protected montane vegetation or mixed with other evergreen forests such as Sidr tree (Ziziphus spinachristi). The Opuntia spp. mostly located in the regions with 1951-2550 m of height. Similarly, scrubland areas, mainly in regions with height of 1330-1950 m. This may be due to soil depth, week geology, and denuded high slope. With increasing altitude, the rock exposed class decreases. The gradient of the slope influences the feature classes' distribution in studied area. Juniper procera has large variation of slope gradient (ranged approx. $80^{\circ}$ ) between 1951 and $2827 \mathrm{~m}$ of elevation range. Whereas in Opuntia spp. It is found that the variation of slope gradient is low (ranged approx. $48^{\circ}$ ) between 1951 and $2550 \mathrm{~m}$ of elevation range. It can be concluded that the slope factor influences and accelerates the growth and expansion of Opuntia spp. in the studied area.

\section{Conclusions}

Raydah protected area in an important declared protected area in Aseer area Kingdom of Saudi Arabia that is rich in biodiversity, and provides habitat for nine of the ten indigenous bird species in the kingdom. Invasive plant species in Raydah could threaten the natural balance among the indigenous species and thereafter affect the biological components of the ecosystem. Assessment of the current situation of the invasive plants in the protected area will provide scientific data base for future management plans to combat and control invasive plants and protect the protected area from their adverse effects.

In this study, the temporal data (i.e. June, Oct and February months) were used to establish a trend in vegetation phenology and changes in species community composition and canopy structures. Comparison of the data from these three months revealed that February was adequate month to detect under story Opuntia spp. Maximum reflection from vegetation occurred in the month of June - October due to full extent (moister types of evergreen forests) in evergreen tree (Sidr tree (Ziziphus spina-christi) and Juniperus procera forests where as during February is shows less reflectance over Sidr tree (Ziziphus spina-christi) and Juniperus procera forests. This pattern in reflection showed that the data acquired between February were suitable for detecting Opuntia spp in the studied area. Every year, the best month varies due to annual temperature and precipitation differences. Opuntia spp's CV was slightly higher than Juniperus procera, indicating that discrimination against Opuntia spp was possible to facilitate more accurate discrimination. The study demonstrated the potential of sentinel sensor for invasive species such as Opuntia spp to be detected and mapped with desirable accuracy. This encouraging result demonstrated the feasibility of developing a semi - automated process for mapping and analysing the distribution of Opuntia spp in forest areas and found better results compared to multispectral data with very high resolution.

Acknowledgements. The author extends his appreciation to the Rector of King Khalid University for supporting this work. This research was conducted during a sabbatical leave. 


\section{REFERENCES}

[1] Abulfatih, H. A., Emara, H. A., Hashish, A. E. (1989): The influence of grazing on vegetation and soil of Asir highlands in south western Saudi Arabia. - Arab Gulf J. Sci. Res. 7: 69-78.

[2] Aref, I. M., El Atta, H. A., Alshahrani, T., Alazba, A., Ahmad, A. I. (2013): Evaluation of the physiological and growth response of Juniperus procera Hochst. Endlicher to some types of microcatchments. - International Journal of Plant, Animal and Environmental Sciences 3(1): 234-241.

[3] Berhanu, A., Tesfaye, G. (2006): The Prosopis dilemma: impacts on dryland biodiversity and some controlling methods. - J. Dryl. 1(2): 158-164.

[4] Boyd, D. S., Foody, G. M. (2011): An overview of recent remote sensing and GIS based research in ecological informatics. - Ecol. Inf. 6(1): 25-36.

[5] Bradley, B. A. (2014): Remote detection of invasive plants: a review of spectral, textural and phenological approaches. - Biol. Invasions 16(7): 1411-1425.

[6] Bradley, B. A., Mustard, J. F. (2006): Characterizing the landscape dynamics of an invasive plant and the risk of invasion using remote sensing. - Ecological Applications 6: 1132-1147.

[7] Branco, S., Videira, N., Branco, M., Paiva, M. R. (2015): A review of invasive alien species impacts on eucalypt stands and citrus orchards ecosystem services: towards an integrated management approach. - J. Environ. Manage. 149: 17-26.

[8] Convention on Biological Diversity (2008): Alien Species that Threaten Ecosystems, Habitats or Species. - FAO, Rome.

[9] Curatola Fernández, G., Silva, B., Gawlik, J., Thies, B., Bendix, J. (2013): Bracken fern frond status classification in the Andes of southern Ecuador: combining multispectral satellite data and field spectroscopy. - Int. J. Rem. Sens. 34(20): 7020-7037.

[10] El-Juhany, L. I., Aref, I. M. (2013): The present status of the natural forests in the southwestern Saudi Arabia: Asir and East Jazan Forests. - World Applied Sciences Journal 21(5) 710-726.

[11] Friis, I. (2009): Cupressaceae. - In: Hedberg, I. et al. (eds.) Flora of Ethiopia and Eritrea. Vol. 1 Lycopodiaceae to Pinaceae. Addis Abeba University, Addis Ababa, Ethiopia \& Uppsala, Sweden, pp. 193-195.

[12] Gaertner, M., Den Breeyen, A., Hui, C., Richardson, D. M. (2009): Impacts of alien plant invasions on species richness in Mediterranean-type ecosystems: a meta-analysis. - Prog. Phys. Geogr. 33(3): 319-338.

[13] Griffiths, B. S., Spilles, A., Bonkowski, M. (2012): C:N:P stoichiometry and nutrient limitation of the soil microbial biomass in a grazed grassland site under experimental $\mathrm{P}$ limitation or excess. - Ecol. Process. 1 1-11. 10.1186/2192-1709-1-6.

[14] Gurevitch, J., Padilla, D. K. (2004): Are invasive species a major cause of extinctions? Trends Ecol. Evol. 19(9): 470-474.

[15] Hejda, M., Pysek, P., Jarosík, V. (2009): Impact of invasive plants on the species richness, diversity and composition of invaded communities. - J. Ecol. 97: 393-403.

[16] IUCN (2011): International Union for Conservation of Nature. http://www.iucn.org/about/union/secretariat/offices/iucnmed/iucn_med_programme/speci es/invasive_species/.

[17] Joshi, C., De Leeuw, J., Van Duren, I. C. (2004): Remote sensing and GIS applications for mapping and spatial modelling of invasive species. - ISPRS 2004: Proceedings of the XXth ISPRS Congress: Geo-Imagery Bridging Continents, 12-23 July 2004, Istanbul, Turkey. Comm. VII., pp. 669-677.

[18] Kingston, N., Waldren, S. (2003): The plant communities and environmental gradients of Pitcairn island: the significance of invasive species and the need for conservation management. - Ann. Bot. 92: 31-40. 
[19] Lawrence, R. L., Bunn, A., Powell, S., Zambon, M. (2004): Classification of remotely sensed imagery using stochastic gradient boosting as a refinement of classification of tree analysis. - Remote Sensing of Environment 90: 331-336.

[20] Lovell, S. J., Stone, S. F., Fernandez, L. (2006): The economic impacts of aquatic invasive species: a review of the literature. - Agric. Res. Econ. Rev. 35(2006): 195-208.

[21] Mallick, J., Singh, R. K., Khan, R. A., Singh, C. K., Kahla, N. B., Warrag, E. I., Islam, S., Rahman, A. (2018): Examining the rainfall - topography relationship using non-stationary modelling technique in semi-arid Aseer region, Saudi Arabia. - Arabian Journal of Geosciences. https://doi.org/10.1007/s12517-018-3580-9.

[22] Mallick, J. Geospatial-based soil variability and hydrological zones of Abha semi-arid mountainous watershed, Saudi Arabia. Arab J. Geosci. 9:281 (2016). DOI 10.1007/s12517-015-2302.

[23] Mallick, J., Y. Alashker, M. Shams, A. Mohd, and A.H. Mohd Risk assessment of soil erosion in semi-arid mountainous watershed in Saudi Arabia by RUSLE model coupled with remote sensing and GIS. Geocarto International. Taylor and Francis. UK.: 1-26 (2014).

[24] Matongera, T. N., Mutanga, O., Dube, T., Lottering, R. T. (2016): Detection and mapping of bracken fern weeds using multispectral remotely sensed data: a review of progress and challenges. - Geocarto Int. 1-16. https://doi.org/10.1080/10106049.2016.1240719.

[25] McNeely, J. A. (2005): Human Dimensions of Alien Invasive Species. - In: Mooney, H. A., Mack, R. N., McNeely, J. A., Neville, L. E., Schei, P. J., Waage, J. K. (eds.) Invasive Alien Species: A New Synthesis. Island Press, Washington, DC, pp. 285-309.

[26] Negash, L. (2010): A Selection of Ethiopia's Indigenous Trees: Biology, Uses and Propagation Techniques. - Addis Ababa University Press, Addis Ababa, Ethiopia.

[27] Niphadkar, M., Nagendra, H. (2016): Remote sensing of invasive plants: incorporating functional traits into the picture. - Int. J. Rem. Sens. 37(13): 3074-3085.

[28] Peerbhay, K., Mutanga, O., Lottering, R., Bangamwabo, V., Ismail, R. (2016): Detecting bugweed (Solanum mauritianum) abundance in plantation forestry using multisource remote sensing. - ISPRS J. Photogrammetry Remote Sens. 121: 167-176.

[29] Peerbhay, K. Y., Mutanga, O., Ismail, R. (2015): Random forests unsupervised classification: the detection and mapping of Solanum mauritianum infestations in plantation forestry using hyperspectral data. - IEEE J. Sel. Top. Appl. Earth Obs. Remote Sens. 8(6): 3107-3122.

[30] Pejchar, L., Mooney, H. A. (2009): Invasive species, ecosystem services and human wellbeing. - Trends Ecol. Evol. 24(9): 497-504.

[31] Pimentel, D., McNair, S., Janecka, J., Wightman, J., Simmonds, C., OConnell, C., Wong, E., Russell, L., Zern, J., Aquino, T., Tsomondo, T. (2001): Economic and environmental threats of alien plant, animal, and microbe invasions, Agric. - Ecosyst. Environ. 84: 1-20.

[32] Pysek, P., Richardson, D. M. (2010): Invasive species, environmental change and management: and health. - Annu. Rev. Environ. Res. 35 pp. 25-55.

[33] Rocchini, D., Andreo, V., Förster, M., Garzon-Lopez, C. X., Gutierrez, A. P., Gillespie, T. W., Hauffe, H. C., He, K. S., Kleinschmit, B., Mairota, P. (2015): Potential of remote sensing to predict species invasions: a modelling perspective. - Prog. Phys. Geogr. 39(3): 283-309.

[34] Sax, D. F., Gaines, S. D. (2008): Species invasions and extinction: the future of native biodiversity on islands. - Proc Nat Acad Sci USA 105: 11490-11497.

[35] Surendra, B., Ahmedin, A. M., Siraj, K. T., Raju, A. J., Solomon (2013): Invasive alien plant species assessment in urban ecosystem: a case study from Andhra University, Visakhapatnam, India. - Int. Res. J. Environment Sci. 2(5): 79-86.

[36] Thomas, J., Mohammed, A. E., Ahmed, H. A, Abdulrehman, Alatar, A., Sivadasan, M., Mohammed, B., Sami, A., Rajakrishnan, R. (2016): Impact of alien invasive species on habitats and species richness in Saudi Arabia. - Journal of Arid Environments. https://doi.org/10.1016/j.jaridenv.2015.10.009. 
[37] Turlings, L. (2000): Invasive Plants and Animals: Is There Away Out? - Netherlands Committee for IUCN, Leiden.

[38] Van Wilgen, B. W., Reyers, B., Le Maitre, D. C., Richardson, D. M., Schonegevel, L. (2008): A biome-scale assessment of the impact of invasive alien plants on ecosystem services in South Africa. - J. Environ. Manage 89: 336-349.

[39] Vincent, P. (2008): Saudi Arabia: An Environmental Overview. - Taylor and Francis, London. https://doi.org/10.1201/9780203030882.

[40] Warrag, E. I., Mallick, J., Singh, R. K., Khan, R. A. (2019): Status of dieback of Juniperus procera (African pencil cedar) in natural stands and plantation in Alsouda Highlands, Saudi Arabia. - Applied Ecology and Environmental Research 17(2): 23252338 .

[41] Wheater, H. S., Larentis, P., Hamilton, G. S. (1989): Design rainfall characteristics for south-west of Saudi Arabia. - Proc. Instn. Civ. Engrs. Part 2: 517-538. 